\title{
Children's response speeds as a function of sex and verbal reinforcement schedule'
}

THOMAS J. RYAN, CARLETON UNIVERSITY

PETER WATSON, UNIVERSITY OF WESTERN ONTARIO

Kindergarten children received 48 lever-pulling trials under conditions of partial (33\%) or continuous (100\%) verbal reinforcement. Over training, partial reinforcement led to increasingly faster speeds relative to continuous reward. These data are consistent with previous researchemploying tangible reinforcers, and with current theoretical formulations of the role of nonreinforcement in partial-reinforcement situations.

Amsel (1958) has postulated that nonattainment of an expected reward leads to the occurrence of frustration, which in turn results in increased motivation. In agreement with the frustrative-nonreward hypothesis, recent studies with children (Bruning, 1964; Ryan, 1966) have shown that partial reward produced faster responding as compared with continuous reward. However, these experiments employed tangible reinforcers such as marbles and candy, and no studies exist, as yet, which apply the frustrative-nonreward hypothesis to socialreinforcement phenomena. Accordingly, the present study investigated the response speeds of children under conditions of partial and continuous verbal reinforcement schedules. If the frustrative-nonreward hypothesis applies to verbal as well as to tangible reward, it was expected that performance would be faster under partial than under continuous verbal reward. In view of the oft-reported finding (see Stevenson, 1965) that boys are more responsive to verbal reinforcement from a female $E$ than is the case for girls, sex of $S$ was included in the design to determine whether this finding could be repeated in a situation markedly different from the more typical marble-dropping task.

Method

The Ss were 16 male and 20 female kindergarten children (58-76 mo.) divided into two groups containing eight males and $\mathbf{1 0}$ females each: two young adult female Es were employed. All Ss received 48 trials on a leverpulling apparatus similar to that described by Ryan (1966). One group (Group 100) was verbally reinforced ("Good," "Very good," or "That's fine") immediately after the completion of each lever - pull, while the other group (Group 33) was rewarded on a random third of the trials. During the 5-sec. intertrial interval, E recorded starting time, from the onset of a stimulus light to initial movement of the lever, and movement time, the time taken to pull the lever from the top to the bottom of its 15-in. excursion, to the nearest .01 sec. Resulfs

Starting and movement times were converted to speeds (1/t sec.) and combined into eight blocks of six trials. Mean starting and movement speeds for each group, which are presented in Fig. 1, were submitted to separate 2 by 2 by 8 analyses of variance, with reinforcement schedule and sex as between-Ss variables, and trial blocks as the within-Ss variable. In neither analysis was the reinforcement schedule main effect significant, while significant blocks main effects, on both starting speed $(F=3.12, d f=7 / 196, p<.01)$ and movement speed $(F=5.73, d f=7 / 196, p<.001)$, indicated a general increase in speeds as training progressed. On starting speed, the presence of a significant reinforcement schedule by blocks interaction $(F=2.73, \mathrm{df}=$ $7 / 196, p=.01$ ) suggested that Group 33 increased significantly over blocks $(F=4.53, \mathrm{df}=7 / 119, \mathrm{p}<.001)$, while Group 100 did not change $(p>.20)$. Analysis of variance performed on the last block of trials, however, indicated that Groups 33 and 100 did not differ significantly $(p>.20)$ by the end of training. For movement speeds, the interaction between blocks and schedule approached significance $(\mathrm{F}=1.50, \mathrm{df}=7 / 196, p<.20)$, suggesting a trend similar to that for starting speeds. All effects for sex were nonsignificant.

Discussion

Demonstration of increasingly fast speeds under partial verbal reward relative to continuous verbal reward is consistent with previous work with tangible rewards (Bruning, 1964; Ryan, 1966) and with Amsel's

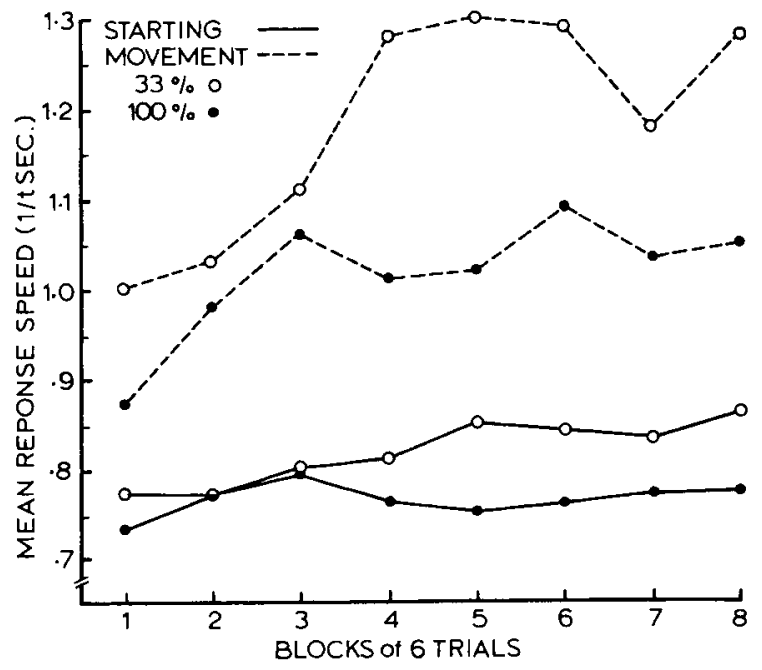

Fig.. 1. Mean starting and movement speeds for Group 33 and Group 100 as a function of 8 blocks of 6 trials. 
(1958) theorizing concerning the motivational effects of nonreinforcement. The present results, however, appear less clear-cut than is the case when tangible reinforcers are employed: asymptotic speeds of the two reinforcement groups in the present experiment did not differ significantly, while Ss who received comparable amounts of training under different schedules of tangible reward did attain different asymptotes.

The absence of significant effects attributable to sex is inconsistent with several studies reviewed by Stevenson (1965); they indicate that Ss are more responsive to social reinforcers when dispersed by an opposite-sex $E$ than when $E$ is of the same sex as S. The present results suggest, however, that this "cross-sex effect" may be situation-specific, i.e., limited to the particular set of experimental conditions described by Stevenson.

\section{References}

Amsel, A. The role of frustrative nonreward in noncontinuous reward situations. Psychol. Bull., 1958, 55, 102-119.

Bruning, J. L. The effects of magnitude of reward and percentage of reinforcement on a lever movement response. Child Develpm., $1964,35,281-285$.

Ryan, T. J..Instrumental performance as related to several reward schedules and age. $J$. exp. child $P$ sychol., 1966 , in press.

Stevenson, H. W. Social reinforcement of children's behavior. In L. P. Lipsitt \& C. C. Spiker (Eds.), Advances in child development and behavior. Vol. 2. New York: Academic Press, 1965.

\section{Note}

1. Preparation of this report was facilitated by National Research Council Grant APB;2. The apparatus was supplied through the Ruth Holton Memorial Fund of the Institute of Child Behavior and Development, State University of Iowa. The authors wish to thank Nora Toll and Judy Rabin for serving as Es, and the London Board of Education for its cooperation in obtaining Ss. 